\title{
Green synthesis of silver/montmorillonite/ chitosan bionanocomposites using the UV irradiation method and evaluation of antibacterial activity
}

\author{
This article was published in the following Dove Press journal: \\ International Journal of Nanomedicine \\ 21 October 2010 \\ Number of times this article has been viewed
}

\author{
Kamyar Shameli' \\ Mansor Bin Ahmad' \\ Wan Md Zin Wan Yunus' \\ Abdolhossein Rustaiyan² \\ Nor Azowa Ibrahim' \\ Mohsen Zargar ${ }^{3}$ \\ Yadollah Abdollahi ${ }^{4}$ \\ 'Department of Chemistry, Faculty \\ of Science, Universiti Putra \\ Malaysia, Serdang, Selangor, Malaysia; \\ ${ }^{2}$ Department of Chemistry, Science \\ and Research Campus, Islamic Azad \\ University, Tehran, Iran; ${ }^{3}$ Faculty of \\ Food Science and Biotechnology, \\ ${ }^{4}$ Institute of Advanced Technology, \\ Universiti Putra Malaysia, Serdang, \\ Selangor, Malaysia
}

\begin{abstract}
In this study, silver nanoparticles (Ag-NPs) were synthesized using a green physical synthetic route into the lamellar space of montmorillonite (MMT)/chitosan (Cts) utilizing the ultraviolet (UV) irradiation reduction method in the absence of any reducing agent or heat treatment. Cts, MMT, and $\mathrm{AgNO}_{3}$ were used as the natural polymeric stabilizer, solid support, and silver precursor, respectively. The properties of $\mathrm{Ag} / \mathrm{MMT} / \mathrm{Cts}$ bionanocomposites (BNCs) were studied as the function of UV irradiation times. UV irradiation disintegrated the Ag-NPs into smaller sizes until a relatively stable size and size distribution were achieved. Meanwhile, the crystalline structure and d-spacing of the MMT interlayer, average size and size distribution, surface morphology, elemental signal peaks, functional groups, and surface plasmon resonance of $\mathrm{Ag} / \mathrm{MMT} / \mathrm{Cts} \mathrm{BNCs}$ were determined by powder X-ray diffraction, transmission electron microscopy, scanning electron microscopy, energy dispersive X-ray fluorescence, Fourier transform infrared, and UV-visible spectroscopy. The antibacterial activity of Ag-NPs in MMT/Cts was investigated against Gram-positive bacteria, ie, Staphylococcus aureus and methicillin-resistant $S$. aureus and Gram-negative bacteria (ie, Escherichia coli) by the disk diffusion method on Muller-Hinton Agar at different sizes of Ag-NPs. All of the synthesized $\mathrm{Ag} / \mathrm{MMT} / \mathrm{Cts} \mathrm{BNCs}$ were found to have high antibacterial activity. These results show that Ag/ $\mathrm{MMT} / \mathrm{Cts} \mathrm{BNCs}$ can be useful in different biologic research and biomedical applications, such as surgical devices and drug delivery vehicles.
\end{abstract}

Keywords: silver nanoparticles, bionanocomposites, montmorillonite, ultraviolet irradiation, chitosan, antibacterial activity

\section{Introduction}

The field of nanotechnology is one of the most active areas of research in recent materials science. Nanoparticles exhibit completely new or improved properties based on specific characteristics, such as size, distribution, and morphology. In addition, nanotechnology is a field that is burgeoning day by day, making an impact in all spheres of human life. New applications of nanoparticles and nanomaterials appear to be emerging rapidly. ${ }^{1-3}$ Many methods can be used for synthesis of metal nanoparticles, including photoreduction or chemical reduction in aqueous medium with various polymer surfactants, ${ }^{4,5}$ chemical reduction in soft matrices (eg, reverse micelles) ${ }^{6}$ or in solid matrices (eg, mesoporous silicate), ${ }^{7}$ and chemical vapor deposition. ${ }^{8}$ Applications have been found for silver nanoparticles (Ag-NPs) in the high-sensitivity fields of biomolecular detection and diagnostics, ${ }^{9}$ antimicrobials and therapeutics, ${ }^{10,11}$
Correspondence: Kamyar Shameli Department of Chemistry, Faculty of Science, Universiti Putra Malaysia, 43400 , Serdang, Selangor, Malaysia Tel +60389466044

Fax +60389466043

Email kamyarshameli@gmail.com 
as well as catalysis ${ }^{12}$ and microelectronics. ${ }^{13}$ However, there is still a need for an economic, commercially viable, and environmentally green route for synthesis of Ag-NPs. Having mentioned that, Ag-NPs can be successfully synthesized using a variety of green irradiation methods, eg, laser, microwave, ultrasonic wave, gamma, ultraviolet (UV), and ion radiation process in aqueous solution and silver salts. ${ }^{14-18}$ Green synthesis of Ag-NPs involves three main steps, which must be evaluated based on green chemistry perspectives, including selection of solvent medium, reducing agent, and nontoxic substances for Ag-NP stability. ${ }^{19}$ Layered silicates, eg, montmorillonite (MMT), have been used in polymer nanocomposites with significant improvement in mechanical properties. ${ }^{20,21}$ MMT possesses a 2-to-1 layered structure with a single octahedral aluminum layer located between two layers of tetrahedral silicon. ${ }^{22}$ Each layer is about $1 \mathrm{~nm}$ thick with a lateral dimension of 100-1000 nm. ${ }^{23}$ Furthermore, MMT as lamellar clay has intercalation, swelling, and ion exchange properties. ${ }^{24}$ It can be delaminated into elemental sheets without difficulty, so it is tempting to utilize these sheets as the substrate for preparation of nanoscale metal by means of electrodeless plating. The MMT interlayer space has been used for the synthesis of material and biomaterial nanoparticles, as support for anchoring transition metal complexes and as adsorbents for cationic ions. ${ }^{24,25}$

Among the natural polymers, chitosan (Cts) has been extensively investigated as a natural cationic biopolymer with excellent biocompatibility, biodegradability, nontoxicity, bioactivity, and multifunctional groups, as well as solubility in aqueous medium for food packaging film, bone substitutes, and artificial skin. Cts can be intercalated in MMT through cationic exchange and hydrogen bonding processes, whereby the resulting bionanocomposites (BNCs) show interesting structural and functional properties. ${ }^{26}$ Conversely, BNCs are made of a natural polymeric matrix and inorganic/organic filler with at least one dimension on the nanometer scale. Metal/clay/polymer compounds as BNCs have become a promising new research field for excellent properties. ${ }^{27}$

Furthermore, Ag-NP products have long been known to have strong bactericidal effects, as well as a broad spectrum of antimicrobial activities, which have been used for centuries to prevent and treat a variety of diseases, most notably infections. Ag-NPs were reported recently as having antibacterial activity against Escherichia coli, Staphylococcus aureus, methicillin-resistant Staphylococcus epidermis (MRSE), and methicillin-resistant S. aureus (MRSA) bacteria. Ag-NPs also exhibit potent cytoprotective activity towards human immunodeficiency virus-infected cells. More recently, the application of Ag-NPs as biologic labels in neuroblastoma cells was reported. Due to the intense plasmon-resonant properties of Ag-NPs and the enhanced resolution obtainable with high-illumination systems in physiologic solutions, studies of the interactions between Ag-NPs and human cells have been possible. ${ }^{28}$

Hence, similar studies of Ag/MMT and Ag/MMT/Cts BNCs with a high percentage of Cts were synthesized by utilizing the UV irradiation method according to our previous work. ${ }^{16,17}$ Here, we report a simple photoreduction method to synthesize Ag-NPs. Using our method, such reductants were not necessary. Instead, we used modified clay (MMT/Cts) as the protective colloid preventing aggregation of Ag-NPs, and it was found that MMT/Cts also assisted in the photoreduction process of silver. In deionized water without MMT and MMT/ Cts, photoreduction is negligible. In this work, we employed a green method for synthesis of $\mathrm{Ag} / \mathrm{MMT} / \mathrm{Cts} \mathrm{BNCs}$ with a low percentage of $\mathrm{Cts}$, and investigated the effects of Ag-NP size on antibacterial properties. In addition, the antibacterial activity of $\mathrm{AgNO}_{3} / \mathrm{MMT} / \mathrm{Cts}$ was investigated and compared with the antibacterial activity of the prepared $\mathrm{Ag} / \mathrm{MMT} / \mathrm{Cts}$ BNCs. Using this method we were able to obtain Ag-NPs of different sizes and with different antibacterial activity by controlling the UV irradiation time.

\section{Materials and methods Materials}

All reagents in this work were of analytic grade and were used as received without further purification. $\mathrm{AgNO}_{3}(99.98 \%)$ was used as the silver precursor, and was obtained from Merck (Darmstadt, Germany). Meanwhile, the MMT powder, used as a solid support for the Ag-NPs, was purchased from Kunipia-F (Tokyo, Japan), and the low molecular weight Cts and glacial acetic acid (HAC, 99\%) were obtained from Sigma-Aldrich (St. Louis, Mo) All the aqueous solutions were used with double-distilled water.

\section{Synthesis of $\mathrm{Ag} / \mathrm{MMT} / \mathrm{Cts} \mathrm{BNCs}$}

For the synthesis of Ag/MMT/Cts BNCs, Cts solution $(100 \mathrm{~mL}$, $0.2 \mathrm{wt} \%$ ) was prepared by solubilizing the $\mathrm{Cts}$ in $1.0 \mathrm{wt} \%$ of HAC solution ( $\mathrm{pH}$-3.45) under constant stirring for one hour. Five hundred milliliters of $\mathrm{AgNO}_{3}(0.02 \mathrm{M})$ was added into the $\mathrm{Cts}$ solution under constant stirring for preparation of the $\mathrm{AgNO}_{3} / \mathrm{Cts}$ solution. For preparation of the MMT suspension, $5.0 \mathrm{~g}$ of MMT was dispersed in $400 \mathrm{~mL}$ double-distilled water and vigorously stirred for one hour. $\mathrm{AgNO}_{3} / \mathrm{Cts}$ were added into the MMT suspension and the mixture was vigorously stirred further for four hours at room temperature to obtain 
the $\mathrm{AgNO}_{3} / \mathrm{MMT} / \mathrm{Cts}$ suspension. The $\mathrm{AgNO}_{3} / \mathrm{MMT} / \mathrm{Cts}$ suspension was irradiated using the UV reactor with a UV lamp at $\lambda=365 \mathrm{~nm}$ while it was stirred at a speed of $195 \mathrm{rpm}$. Irradiation times of one hour (A1), three hours (A2), 18 hours (A3), 48 hours (A4), and 96 hours (A5) were applied, respectively, for the different cuvettes. The obtained Ag/MMT/Cts BNC suspensions were then centrifuged, washed four times in the double-distilled water in order to remove any $\mathrm{Ag}^{+}$residue, and dried at $40^{\circ} \mathrm{C}$ under vacuum overnight. All the experiments were conducted at ambient temperature.

\section{Evolution of antibacterial activity}

The in vitro antibacterial activity of the samples was evaluated using the Mueller-Hinton Agar disc diffusion method with determination of inhibition zones in $\mathrm{mm}$, and conforming to the recommended standards of the National Committee for Clinical Laboratory Standards. E. coli (American Type and Culture Collection [ATCC] 25922), S. aureus (ATCC 25923), and MRSA (ATCC 700689) were used for the antibacterial effect assay. Briefly, sterile paper discs (6 mm) impregnated with $20 \mu \mathrm{L}$ of $\mathrm{Ag} / \mathrm{MMT} / \mathrm{Cts} \mathrm{BNCs}$ (A2, A4, and A5) with different treatment times were suspended in the sterile distilled water and were left to dry at $37^{\circ} \mathrm{C}$ for 24 hours in sterile conditions. The bacterial suspension was prepared by making a saline suspension of isolated colonies selected from 18 to 24 hours of tryptic soy agar plating. The suspension was adjusted to match the tube of $0.5 \mathrm{McF}$ arland turbidity standard using spectrophotometry at $600 \mathrm{~nm}$, which equals $1.5 \times 10^{8}$ colony-forming units $/ \mathrm{mL}$. The surface of the Mueller-Hinton Agar was completely inoculated using a sterile swab, which was steeped in the prepared suspension of bacteria. Finally, the impregnated discs were placed on the inoculated agar and incubated at $37^{\circ} \mathrm{C}$ for 24 hours. After incubation, the diameter of the growth inhibition zones was measured. Chloramphenicol $30 \mu \mathrm{g}$ and cefotaxime $30 \mu \mathrm{g}$ were used as the positive standards in order to control the sensitivity of the bacteria. All tests were done in triplicate.

\section{Characterization methods and instruments}

The prepared Ag/MMT/Cts BNCs were characterized by UV-visible spectroscopy, powder X-ray diffraction, transmission electron microscopy, and Fourier transform infrared spectroscopy, scanning electron microscopy, energy dispersive X-ray fluorescence spectrometry, and Fourier transform infrared spectroscopy. The UV-visible spectra were recorded over the range of 300-700 nm using the H.UV.1650 PC UV-visible spectrophotometer (Shimadzu, Tokyo, Japan).
Structures of the $\mathrm{Ag} / \mathrm{MMT} / \mathrm{Cts} \mathrm{BNC}$ s produced were examined using Shimadzu powder X-ray diffraction-6000. Changes in the interlamellar spacing of MMT and Ag/MMT/Cts BNCs were also studied by powder $\mathrm{X}$-ray diffraction in the angle range of $2^{\circ}<2 \theta<10^{\circ}$. In addition, the interlamellar spaces were calculated from the powder X-ray diffraction peak positions using Bragg's law. A wavelength $(\lambda)$ of $0.15418 \mathrm{~nm}$ was used for these measurements. Powder X-ray diffraction patterns were recorded at a scan speed of $2^{\circ} \mathrm{min}^{-1}$. Transmission electron microscopy observations were carried out on a H-7100 electron microscope (Hitachi, Tokyo, Japan) and the particle size distributions were determined using the UTHSCSA Image Tool program (V. 3.00; University of Texas Health Science Center, San Antonia, TX). Scanning electron microscopy was performed utilizing the XL-30 instrument (Philips, Amsterdam, The Netherlands) to study the morphology of MMT, MMT/Cts, and Ag/MMT/Cts BNCs (A5). Furthermore, energy dispersive X-ray fluorescence spectrometry was carried out on a Shimadzu EDX-700HS spectrometer. Fourier transform infrared spectra were recorded over the range of $400-4000 \mathrm{~cm}^{-1}$ utilizing a Series 100 Perkin Elmer FT-IR 1650 spectrophotometer (Perkin Elmer, Walthman, MA). The reactions were carried out on a UV reactor $(6 \mathrm{~W})$. After the reactions, the samples were centrifuged using a high-speed centrifuge machine (Avanti J25; Beckman, Brea, CA).

\section{Results}

The mechanism of the $\mathrm{Ag} / \mathrm{MMT} / \mathrm{Cts} \mathrm{BNC}$ s synthesized from $\mathrm{AgNO}_{3} / \mathrm{MMT} / \mathrm{Cts}$ produced by $\mathrm{UV}$ irradiation reduction is depicted schematically in Figure 1. During UV irradiation, the reduction and fragmentation of large Ag-NPs happen simultaneously. The small sizes of Ag-NPs were intercalated into the lamellar space of MMT/Cts utilizing the UV irradiation reduction method in the absence of any chemical reducing agent or heat treatment. The color of the prepared samples at different UV irradiation times gradually changed from colorless for $\mathrm{AgNO}_{3} / \mathrm{MMT} / \mathrm{Cts}$ to light gray, then to gray, and finally to dark gray, indicating the formation of AgNPs in the MMT/Cts suspension (Figure 2). The formation of Ag-NPs was also followed by measuring the surface plasmon resonance bands of $\mathrm{AgNO}_{3} / \mathrm{MMT} / \mathrm{Cts}$ (A0) and $\mathrm{Ag} / \mathrm{MMT} / \mathrm{Cts} \mathrm{BNCs}$ suspensions (A1-A5) at wavelengths in the 300-700 $\mathrm{nm}$ range (Figure 3). Comparison between the powder X-ray diffraction patterns of MMT, MMT/Cts, and $\mathrm{Ag} / \mathrm{MMT} / \mathrm{Cts} \mathrm{BNCs}$ (A2, A4, and A5) in the small angle range of $2 \theta\left(2^{\circ}<2 \theta<10^{\circ}\right)$ indicated the formation of the intercalated Ag-NP structure (Figure 4). Powder X-ray diffraction patterns in the wide angle range of $2 \theta\left(30^{\circ}<2 \theta\right.$ 
A

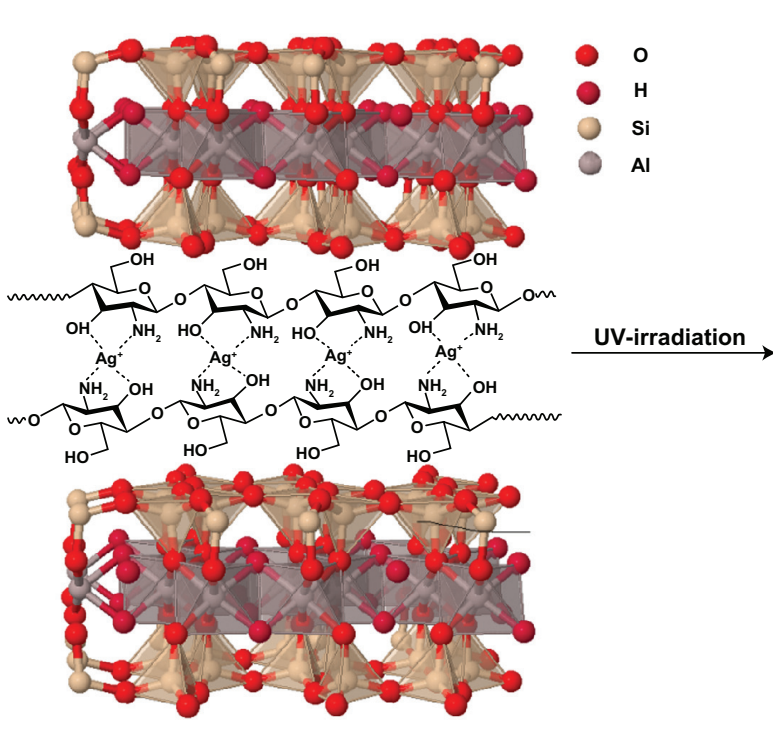

B

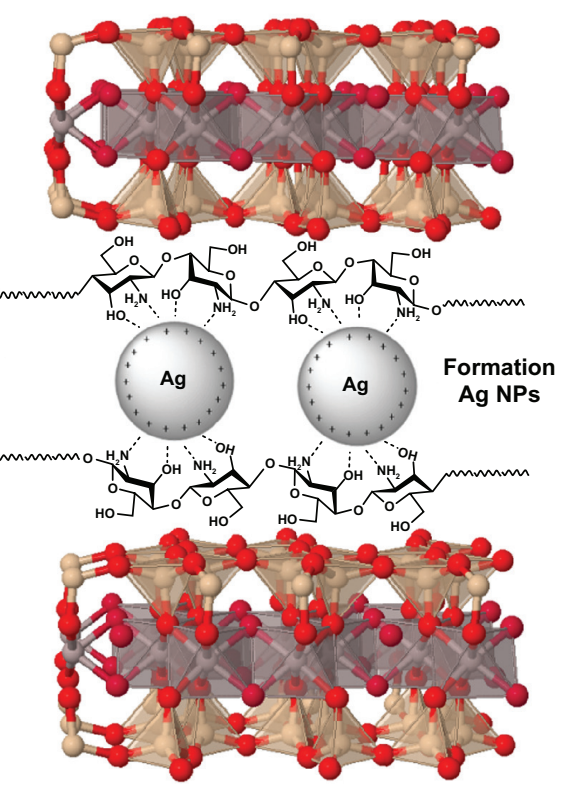

Figure I Schematic illustration of the synthesized silver/montmorillonite/chitosan bionanocomposites from silver nitrate/montmorillonite/chitosan (A0) by ultraviolet irradiation method.

$<80^{\circ}$ ) were also employed to determine the crystalline structures of the synthesized Ag-NPs (Figure 5). Transmission electron microscopy images and size distributions of the Ag-NPs showed the mean diameter of the nanoparticles, which were mostly in the 3.16-10.97 nm range (Figure 6). Scanning electron microscopy images indicated that there were structural changes between the initial MMT, MMT/ $\mathrm{Cts}$, and $\mathrm{Ag} / \mathrm{MMT} / \mathrm{Cts} \mathrm{BNCs}$ under a longer UV irradiation time. Additionally, the energy dispersive X-ray fluorescence spectra for the MMT, MMT/Cts, and Ag/MMT/Cts BNCs (A5) confirmed the presence of elemental compounds in the MMT, Cts, and Ag-NPs without any other impurity peaks (Figure 7). The chemical structures of the MMT, MMT/ $\mathrm{Cts}$, and $\mathrm{Ag} / \mathrm{MMT} / \mathrm{Cts}$ BNCs were analyzed using Fourier

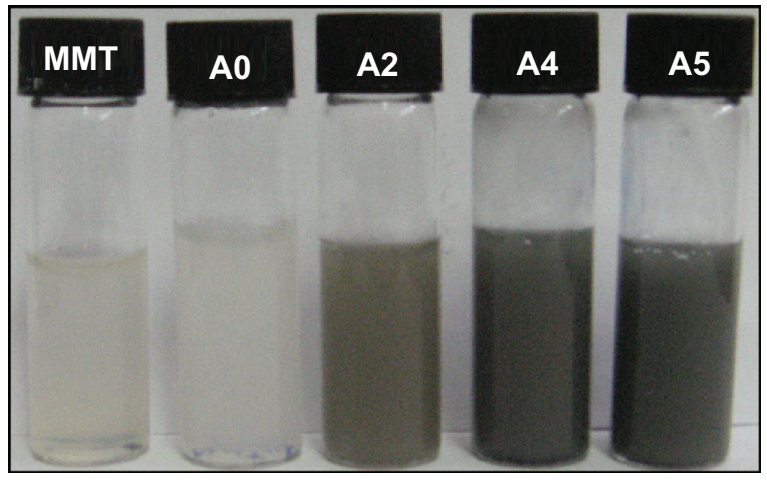

Figure 2 Photograph of montmorillonite, silver nitrate/montmorillonite/chitosan (A0), silver/montmorillonite/chitosan bionanocomposites (A2, A4, and A5) for 3, 48, and 96 hours of ultraviolet irradiation times. transform infrared spectroscopy (Figures 8 and 9). The antibacterial studies showed comparable effects for all samples between MMT, $\mathrm{AgNO}_{3} / \mathrm{MMT} / \mathrm{Cts}$ (A0), and $\mathrm{Ag} / \mathrm{MMT} / \mathrm{Cts}$ BNCs (A2, A4, and A5) against different bacteria as indicated by the inhibition zone test (Figure 10 and Table 1).

\section{Discussion}

There have been numerous studies on irradiation reduction of Ag-NPs in water and other solutions. It has been shown that the $\mathrm{Ag}^{+}$ions are reduced by the $e_{a q}^{-}$hydrated electrons produced during irradiation in solution. ${ }^{29,30}$ The irradiation reduction process can be written as follows:

$$
\begin{gathered}
n^{\bullet} \mathrm{H}_{2} \mathrm{O} \stackrel{\text { irradiation }}{\longrightarrow} e_{a q}^{-}+\mathrm{H}^{\bullet}+\mathrm{OH}^{\bullet}+\mathrm{H}_{3} \mathrm{O}^{+}+\mathrm{H}_{2}+\cdots, \\
\mathrm{AgNO}_{3} \rightarrow \mathrm{Ag}^{+}+\mathrm{NO}_{3}^{-} \\
\mathrm{Ag}^{+}+e_{a q}^{-} \stackrel{\text { reduction }}{\longrightarrow} \mathrm{Ag}^{0}
\end{gathered}
$$

because the hydrogen atoms formed by the $e_{a q}^{-}$hydrated electrons in the acetic water solution can also reduce the $\mathrm{Ag}^{+}$ ions. The neutral atom $\mathrm{Ag}^{0}$ is found to react with $\mathrm{Ag}^{+}$ions to form relatively stable $\mathrm{Ag}$ clusters. ${ }^{31,32}$

$$
\begin{gathered}
\mathrm{Ag}^{0}+\mathrm{Ag}^{+} \rightarrow \mathrm{Ag}_{2}^{+} \\
n \mathrm{Ag}^{+}+\mathrm{Ag}_{2}^{+} \rightarrow(\mathrm{Ag})_{n}^{+} \\
(\mathrm{Ag})_{n}^{+}+n e_{a q}^{-} \rightarrow(\mathrm{Ag})_{n}
\end{gathered}
$$




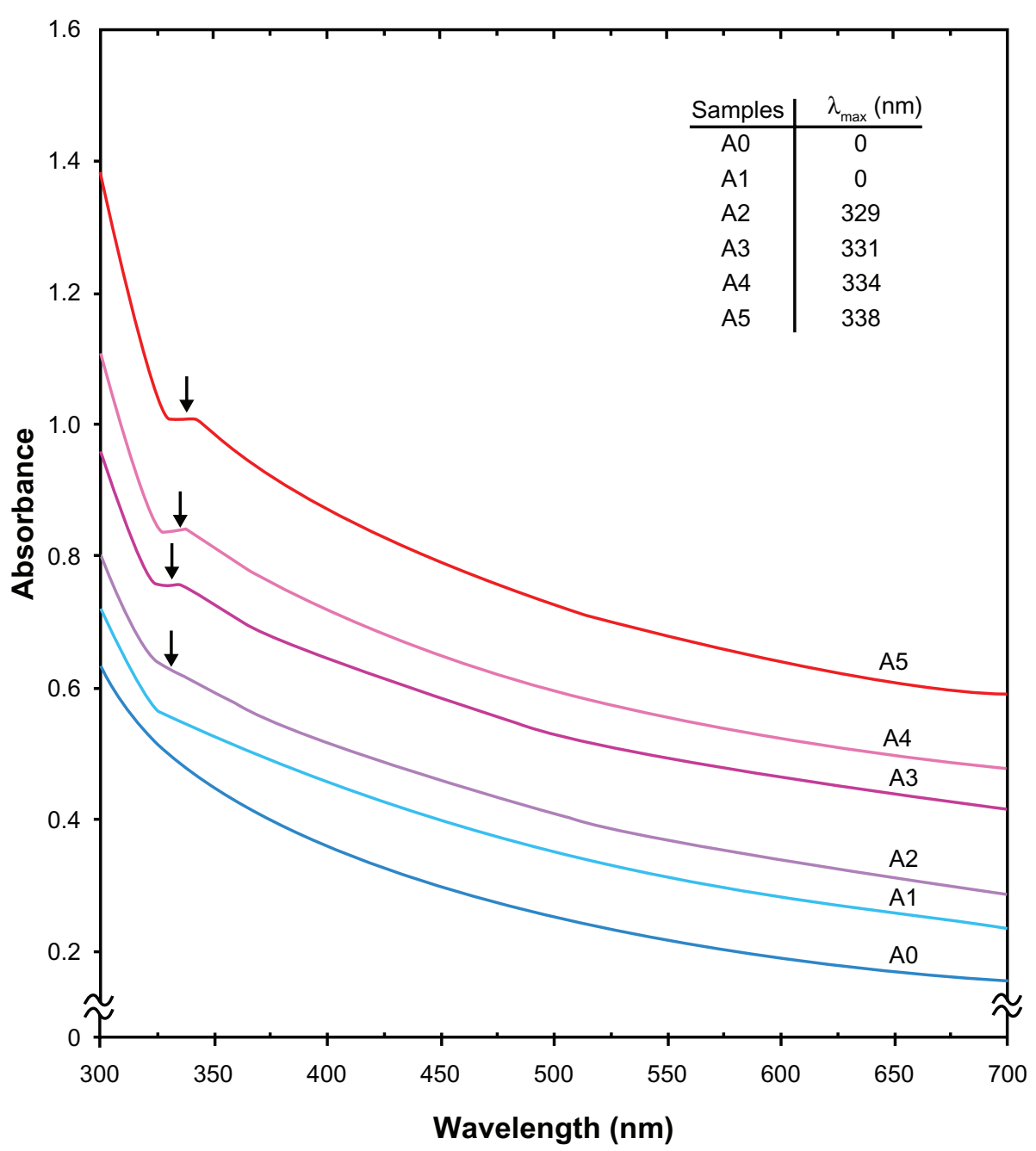

Figure 3 Ultraviolet-visible adsorption spectra of silver nitrate/montmorillonite/chitosan (A0) and silver/montmorillonite/chitosan bionanocomposites (AI-A5) at different ultraviolet irradiation times.

Photoinduced fragmentation of Ag-NPs has been reported by Kamat et al, ${ }^{33}$ and can be summarized in the following reaction scheme through a biphotonic process:

$$
\begin{gathered}
(\mathrm{Ag})_{n}+2 h v \rightarrow(\mathrm{Ag})_{n}^{+}+n e_{a q}^{-} \\
(\mathrm{Ag})_{n}^{+}+e_{a q}^{-} \rightarrow(\mathrm{Ag})_{n} \\
(\mathrm{Ag})_{n}^{+} \rightarrow(\mathrm{Ag})_{n-1}+\mathrm{Ag}^{+}
\end{gathered}
$$

where:

$(\mathrm{Ag})_{n}=$ silver nanocluster containing $n$ silver atom $e_{a q}^{-}=$aqueous electron

These clusters then gather or absorb the neutral $\mathrm{Ag}^{0}$ to form Ag-NPs. In this study, we used Cts as a stabilizer to prevent formation of larger particles in solution and as a modifier to improve MMT layers. We intended to study primarily the Ag-NPs formed in the MMT/Cts acetic water suspension.
A detailed discussion of the photoreduction mechanism has been published elsewhere. ${ }^{34-36}$

\section{UV-visible spectroscopy}

The characteristic of the silver surface plasmon resonance bands was detected to be around $330 \mathrm{~nm}$ (Figure 3). These absorption bands were presumably corresponding to Ag-NPs smaller than $10 \mathrm{~nm} .{ }^{4}$ However, there was no characteristic UV-visible absorption of Ag-NPs before UV irradiation for the $\mathrm{AgNO}_{3} / \mathrm{MMT} / \mathrm{Cts}$ suspension (A0). A nanosilver surface plasmon resonance band was detected at around $329 \mathrm{~nm}$ when the duration of UV irradiation exceeded three hours. For A3 and $\mathrm{A} 4$, the absorbance was observed at 331 and $334 \mathrm{~nm}$, respectively, and its intensity obviously had increased compared with A2. Increased absorbance with further UV irradiation time indicated that the concentration of Ag-NPs had increased, ${ }^{37}$ because the photoinduced fragmentation of Ag-NPs had increased the total number of particles in 


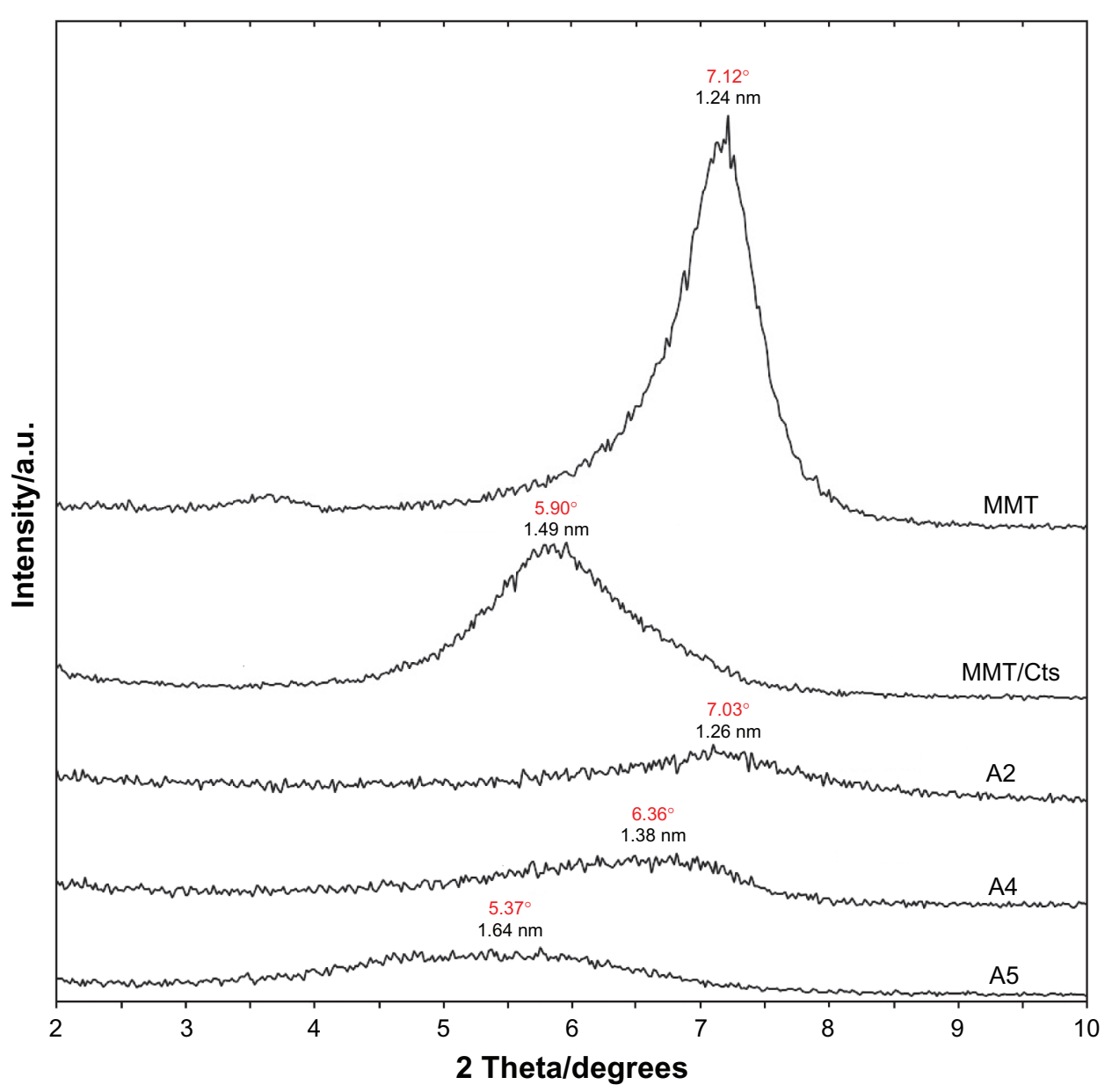

Figure 4 Powder X-ray diffraction, patterns of montmorillonite, montmorillonite/chitosan, and silver/montmorillonite/chitosan bionanocomposites for (A2) three hours, (A4), 48 hours, and (A5) 96 hours of ultraviolet irradiation times.

solution. As for A5, the absorbance increased considerably and was red-shifted to $338 \mathrm{~nm}$. This was consistent with the earlier findings that higher concentrations of metal nanoparticles might also lead to red-shift of the surface plasmon resonance band. ${ }^{38}$

\section{X-ray diffraction}

As shown in Figure 4, the original d-spacing $\left(d_{s}\right)$ of MMT, $1.24 \mathrm{~nm}$ and in MMT/Cts, was increased to $1.49 \mathrm{~nm}$ at the small $2 \theta$ angles $\left(2 \theta=7.12^{\circ}\right.$ for MMT and $2 \theta=5.90^{\circ}$ for MMT/Cts) by Cts intercalation. The $\mathrm{d}_{\mathrm{s}}$ in A2, A4, and A5 also increased gradually from $1.26 \mathrm{~nm}$ to $1.38 \mathrm{~nm}$ and, finally, to $1.64 \mathrm{~nm}$ at the $2 \theta$ angles $\left[2 \theta=7.03^{\circ}\right.$ (A2), $2 \theta=6.36^{\circ}$ (A4), and $2 \theta=5.37^{\circ}$ (A5)] by Ag/Cts intercalation. These $d_{S}$ values were direct proof of the intercalation structures. The Ag-NPs formed at the latter location were the cause of the increase in basal spacing. In these samples, the intensities of the reflections were significantly lower, whereas their half-widths were larger than those of undoped clay minerals, whereby the highly ordered parallel lamellar structure of the mineral was disrupted by metal nanoparticle formation. ${ }^{39}$ In addition, all the $\mathrm{Ag} / \mathrm{MMT} / \mathrm{Cts} \mathrm{BNCs}$ (A1-A5) had a similar diffraction profile and the powder X-ray diffraction peaks at $2 \theta$ of $38.24^{\circ}, 44.43^{\circ}, 64.62^{\circ}$, and $77.50^{\circ}$ (Figure 5) could be attributed to the $111,200,220$, and 311 crystallographic planes of the face-centered cubic silver crystals, respectively. ${ }^{34}$ For all samples, the main crystalline phase was silver, and no obvious other phases as impurities were found in the powder X-ray diffraction patterns. Moreover, the powder X-ray diffraction peak broadenings of Ag-NPs were mostly due to the existing nanosized particles in the BNCs. ${ }^{40}$ In addition, there was a characteristic peak at about $2 \theta=61.62^{\circ}$ related to the MMT clay (powder X-ray diffraction Ref. No. 00-003-0010) as a stable substrate. The intensities of $111,200,220$, and 311 reflections due to the Ag-NPs phase were also found to increase along with the increased Ag-NPs content in the UV irradiation durations. 


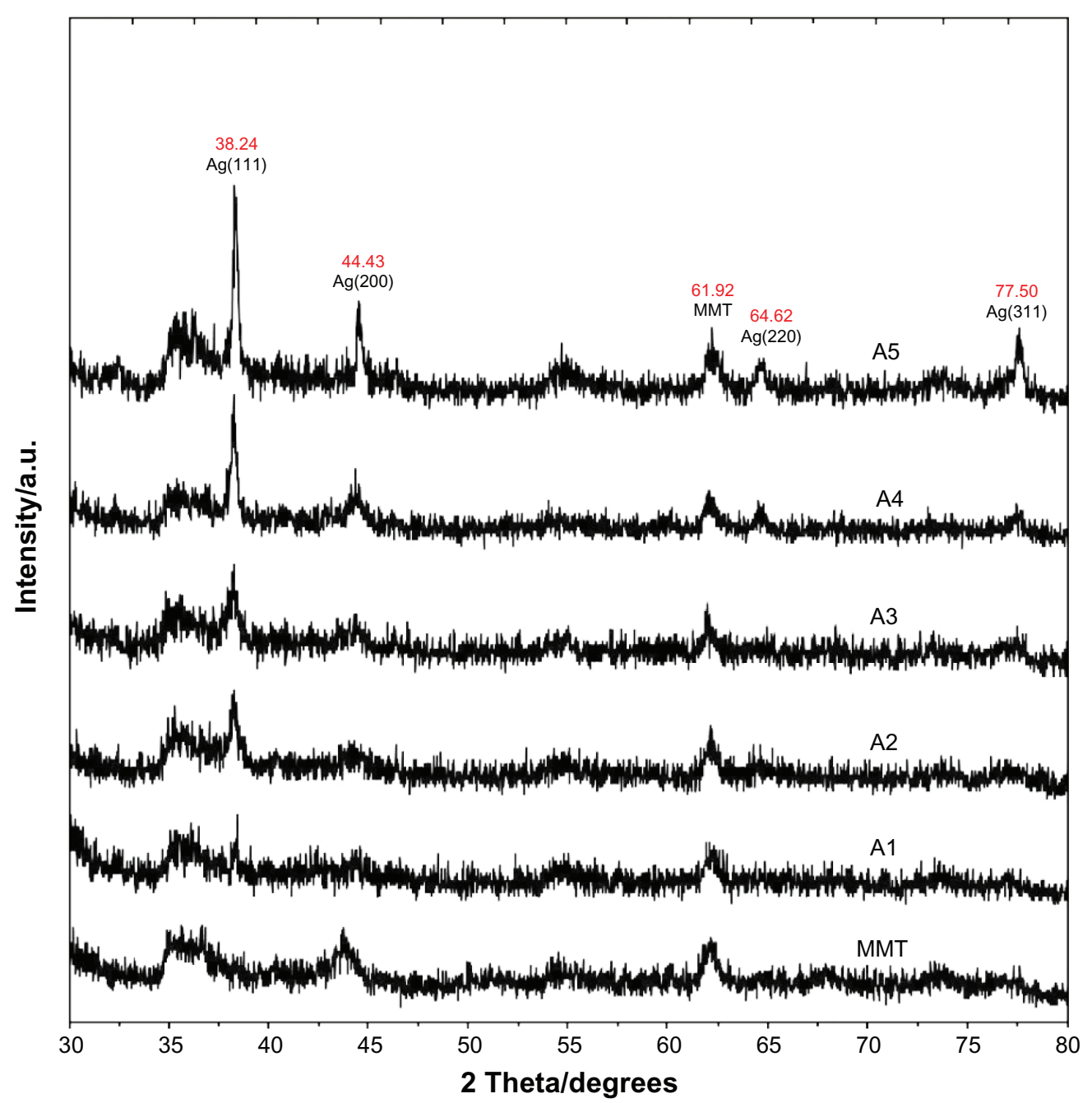

Figure 5 Powder X-ray diffraction patterns of montmorillonite, silver/montmorillonite/chitosan bionanocomposites for different ultraviolet irradiation times (AI) I hour, (A2) 3 hours, (A3) 18 hours, (A4) 48 hours, and (A5) 96 hours.

\section{Morphology}

Transmission electron microscopy images and corresponding $\mathrm{Ag} / \mathrm{MMT} / \mathrm{Cts} \mathrm{BNC}$ particle size distributions are shown in Figure 6. When the $\mathrm{AgNO}_{3} / \mathrm{MMT} / \mathrm{Cts}$ suspension was irradiated under UV light for three hours (A2), photoreduced Ag-NPs were formed, with a broad size distribution and a mean diameter of about $10.97 \pm 5.60 \mathrm{~nm}$ (Figures 6a, 6b). As the irradiation time was increased in A4, the mean diameter of Ag-NPs decreased considerably to $5.58 \pm 2.76 \mathrm{~nm}$ (Figures $6 \mathrm{c}, 6 \mathrm{~d}$ ) as compared with A2. This observation is consistent with earlier findings by other researchers that larger Ag-NPs were obtained under shorter irradiation time, but disintegrated under further UV irradiation..$^{41}$ There was a less significant decrease in the particle size for samples irradiated at 96 hours, A5 $(3.16 \pm 0.80 \mathrm{~nm})$, when compared with that for 48 hours (Figures 6e, 6f). The result shows a narrow size distribution for Ag-NPs, indicating that thee particles are highly homogeneous after 96 hours.

Scanning electron microscopy images of the MMT, MMT/ $\mathrm{Cts}$, and $\mathrm{Ag} / \mathrm{MMT} / \mathrm{Cts}$ (A5) are presented in Figure 7. The surface morphology of MMT demonstrates a layered surface with some large flakes, which is a typical structure for MMT (Figure 7a). The exterior morphology for MMT/Cts and Ag/ MMT/Cts, both irradiated for 96 hours, show layered surfaces with short flakes and without significant morphologic differences between them. Furthermore, the external surfaces of $\mathrm{Ag} /$ $\mathrm{MMT} / \mathrm{Cts} \mathrm{BNCs}$ are shining due to the presence of Ag-NPs (Figures 7c, 7e). Figures 7b, 7d, and 7f show the energy dispersive X-ray fluorescence spectra for the MMT, MMT/Cts, and $\mathrm{Ag} / \mathrm{MMT} / \mathrm{Cts} \mathrm{BNCs}$. The peaks around 1.7, 2.7, 2.9, 6.4, and $7.1 \mathrm{keV}$ are related to the binding energies of MMT, the peaks about $8.1,8.7$, and $9.6 \mathrm{keV}$ are corresponding to the binding energies of Cts, and the peaks around 1.3,3.1,3.3, and $3.4 \mathrm{keV}$ 

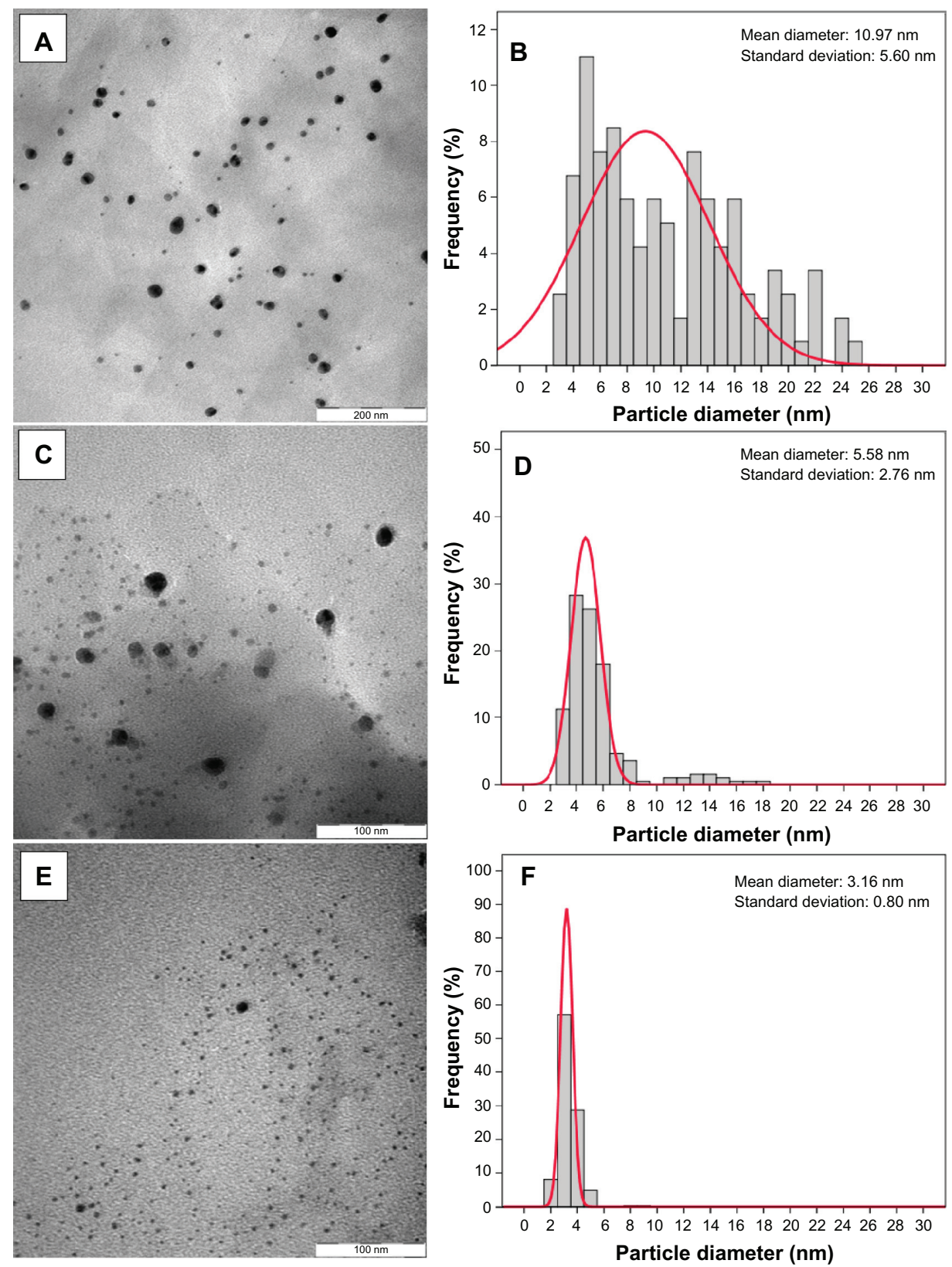

Figure 6 Transmission electron microscopy images and their corresponding particle size distributions of silver/montmorillonite/chitosan bionanocomposites for A2 (A, B), A4 (C, D), and A5 (E, F).

related to silver elements in the A5. ${ }^{42}$ Additionally, the energy dispersive X-ray fluorescence spectra for the MMT, MMT/ Cts, and $\mathrm{Ag} / \mathrm{MMT} / \mathrm{Cts}$ BNCs (A5) confirmed the presence of elemental compounds in the MMT, Cts, and Ag-NPs without any impurity peaks. The results indicate that the synthesized BNCs are composed of high purity Cts and Ag-NPs.

\section{Fourier transform infrared chemical analysis}

The Fourier transform infrared spectrum of MMT (Figure 8c) showed vibration bands at $3630 \mathrm{~cm}^{-1}$ for $\mathrm{O}-\mathrm{H}$ stretching,
$3421 \mathrm{~cm}^{-1}$ due to interlayered $\mathrm{O}-\mathrm{H}$ stretching (H bonding), at 1644 and $1561 \mathrm{~cm}^{-1}$ for H-O-H bending, 1121, 1006, and $910 \mathrm{~cm}^{-1}$ for Si-O stretching, $623 \mathrm{~cm}^{-1}$ for Al-OH, $910 \mathrm{~cm}^{-1}$ due to $(\mathrm{Al}, \mathrm{Mg})-\mathrm{OH}$ vibration modes, and 523 and $436 \mathrm{~cm}^{-1}$ for Si-O bending. ${ }^{43}$ The spectrum of Cts (Figure $8 \mathrm{a}$ ) showed peaks at 3375 and $3320 \mathrm{~cm}^{-1}$ due to overlapping of $\mathrm{O}-\mathrm{H}$ and N-H stretching bands, ie, $2900 \mathrm{~cm}^{-1}$ for aliphatic C-H stretching, 1652 and $1612 \mathrm{~cm}^{-1}$ for N-H bending, 1434, 1386 , and $1333 \mathrm{~cm}^{-1}$ for $\mathrm{C}-\mathrm{H}$ bending, and $1051 \mathrm{~cm}^{-1}$ for $\mathrm{C}-\mathrm{O}$ stretching. The spectrum of MMT/Cts (Figure 8b) showed the combination of characteristic absorptions due to 

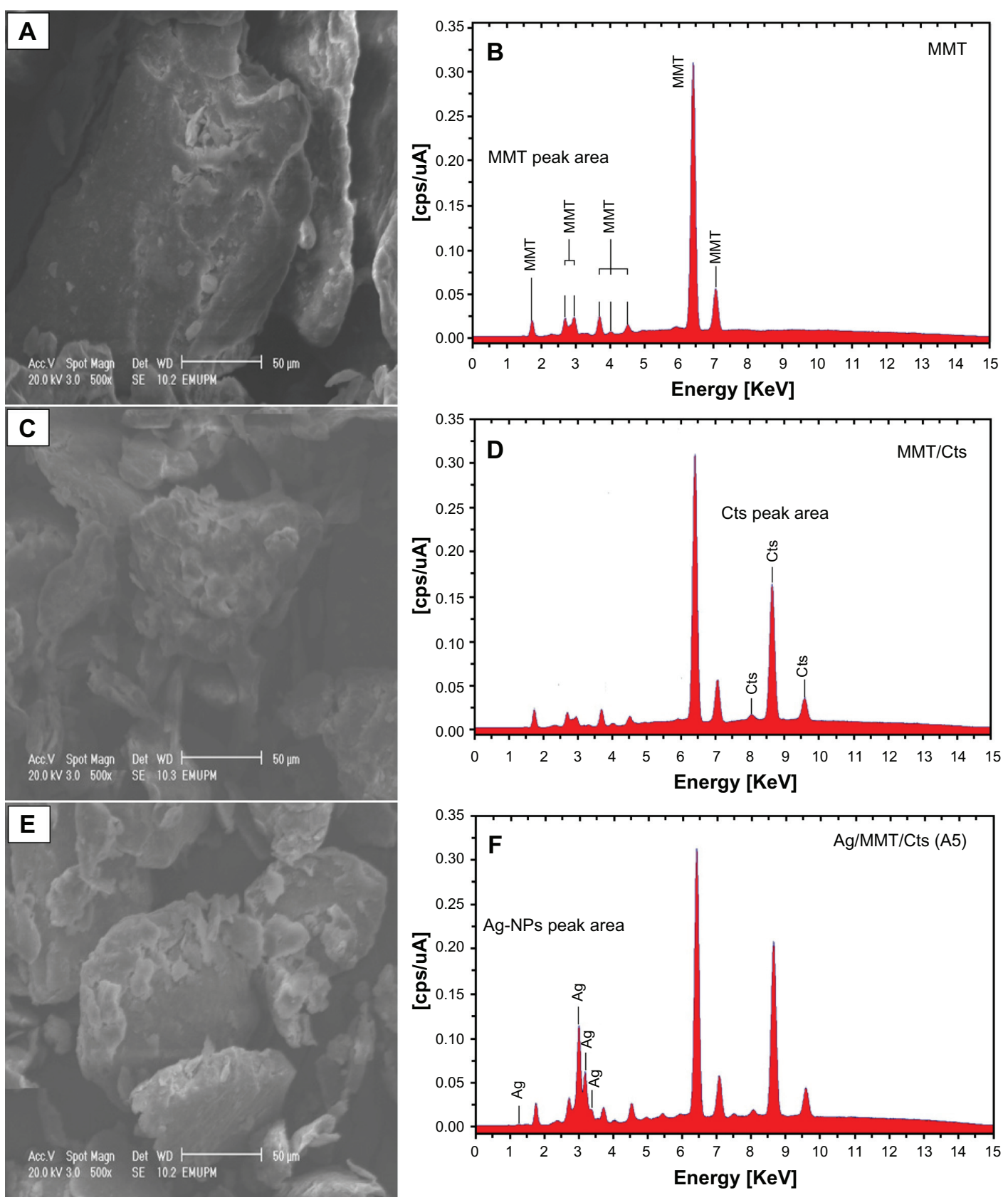

Figure 7 Scanning electron microscopy micrographs and energy dispersive x-ray fluorescence spectra, respectively, for the montmorillonite (A, B), montmorillonite/ chitosan (C, D) and silver/montmorillonite/chitosan bionanocomposites [A5 (E, F)].

the MMT and amine groups of Cts. Peaks for the external vibration and interlayered stretching $\mathrm{O}-\mathrm{H}$ groups in MMT and MMT/Cts were constant at 3630 and $3421 \mathrm{~cm}^{-1}$. On the other hand, the peaks of aliphatic $\mathrm{C}-\mathrm{H}$ and $-\mathrm{NH}_{2}$ groups in pure Cts at 2900, 1652, and $1612 \mathrm{~cm}^{-1}$ were shifted to 2925,1644 , and $1560 \mathrm{~cm}^{-1}$ in the MMT/Cts, corresponding to deformation vibration of the amine group in Cts. ${ }^{44,45}$ These results appeared to be in agreement with data from powder X-ray diffraction, revealing intercalation of Cts in the MMT structure. As shown in Figure 9, there was no significant change in the spectra of MMT/Cts and Ag/MMT/ Cts BNCs, except for disappearance of the peak at 1391 and $1343 \mathrm{~cm}^{-1}$ for MMT/Cts and existence of the peak at 1417 and $1353 \mathrm{~cm}^{-1}$ due to complexation between amino groups of the Cts and Ag-NPs.

\section{Antibacterial study}

Inhibition zone values were obtained for the synthesized nanoparticles tested against E. coli, S. aureus, and MRSA. Results and images for the inhibition zones are presented 


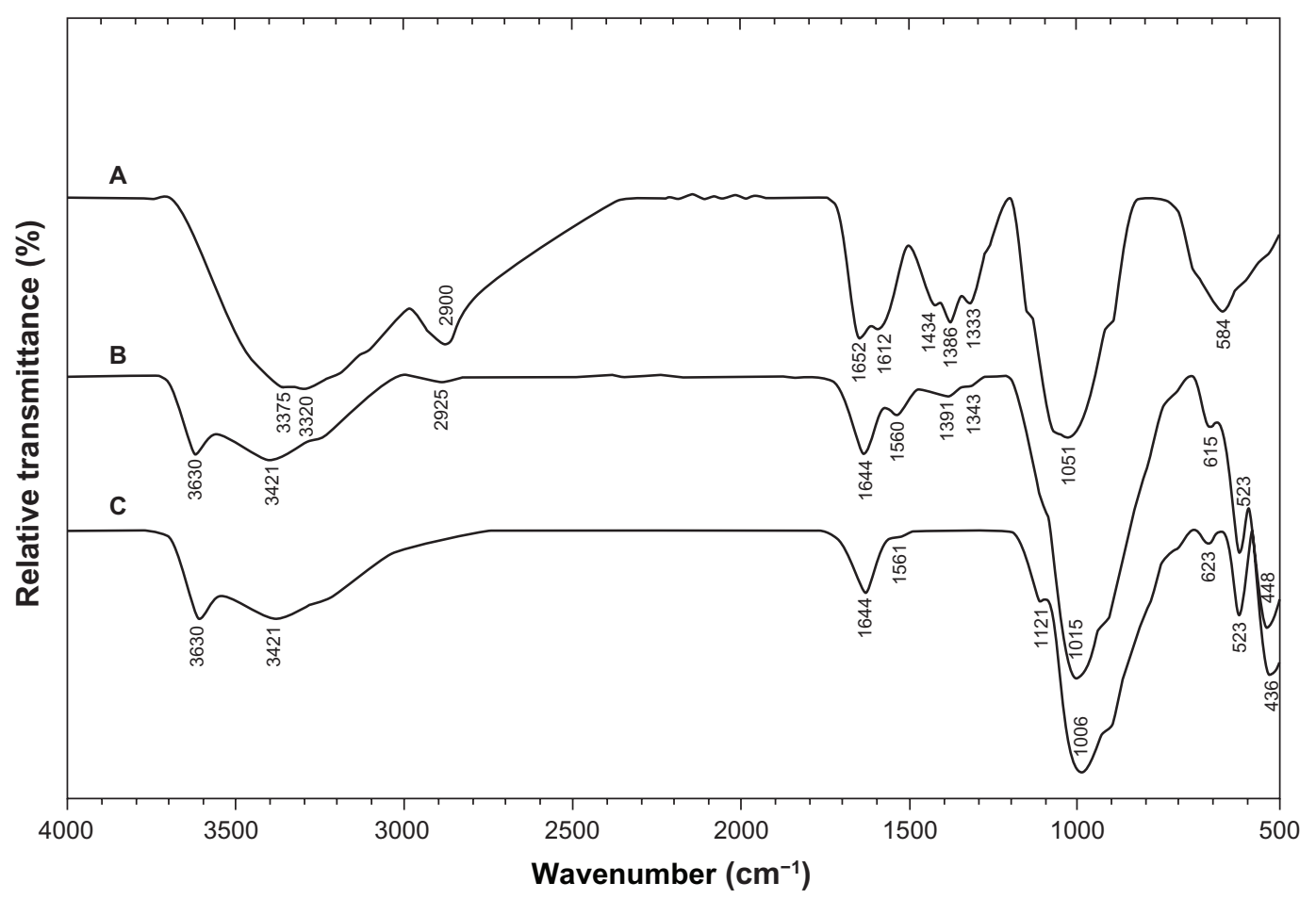

Figure 8 Fourier transform infrared spectra for A) chitosan, B) montmorillonite/chitosan, and C) montmorillonite.

as average values in the Table and Figure 10, respectively. The table shows that the Ag-NPs had high and similar antibacterial activity against Gram-positive and Gramnegative bacteria. Because of their size, Ag-NPs can easily reach the nuclear content of bacteria and they present the greatest surface area. Thus, the contact with bacteria was the greatest. ${ }^{46}$ The $\mathrm{Ag} / \mathrm{MMT} / \mathrm{Cts} \mathrm{BNCs}$ suspensions were used in the form in which they had been prepared. Therefore, antibacterial tests of solutions containing the reaction components were performed.

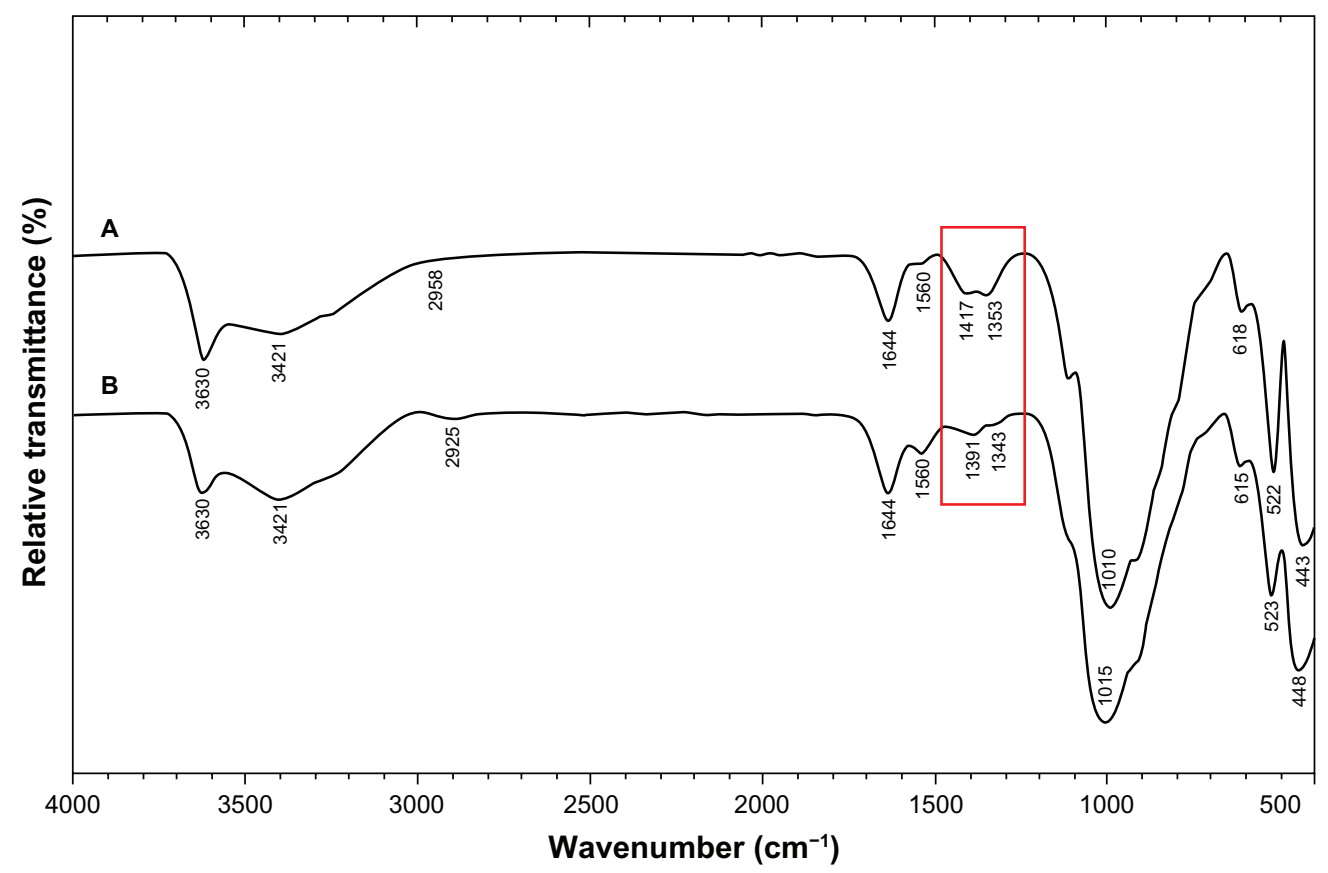

Figure 9 Fourier transform infrared spectra of A) silver/montmorillonite/chitosan bionanocomposites for (A5) and B) montmorillonite/chitosan. 


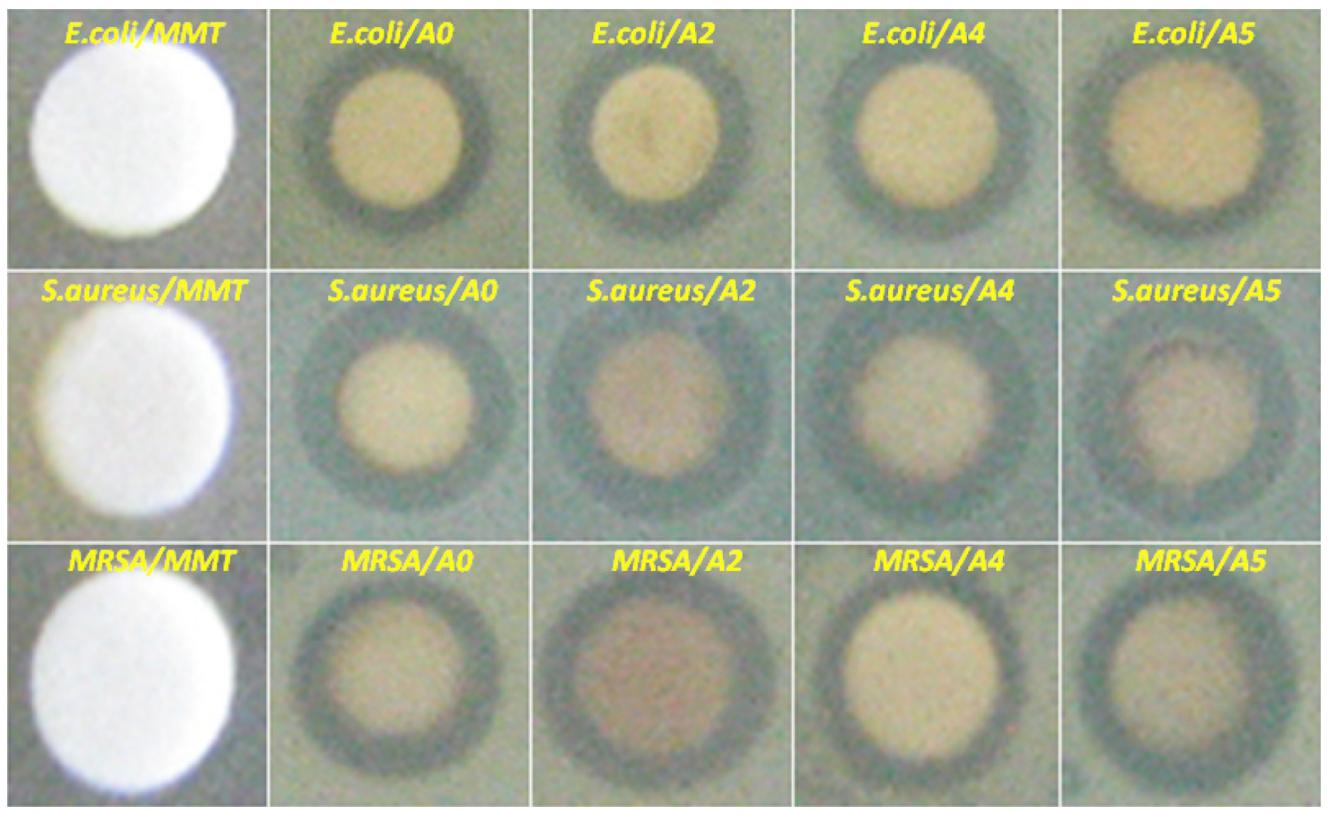

Figure 10 Comparison of the inhibition zone test between montmorillonite, silver nitrate/montmorillonite/chitosan (A0), and silver/montmorillonite/chitosan bionanocomposites (A2, A4, and A5) against different bacteria.

\section{Conclusion}

The Ag-NPs were successfully prepared from the $\mathrm{AgNO}_{3} /$ $\mathrm{MMT} / \mathrm{Cts}$ suspension by using the UV irradiation as a green method in the interlamellar space of MMT without any heat treatment or reducing agent. These Ag-NPs were found to be stabilized by the low molecular weight of Cts. In addition, the distribution size of Ag-NPs prepared at different UV irradiation times indicated that larger Ag-NPs were obtained when irradiated for three hours. Further experiments showed that the increase in UV irradiation time caused a decrease in particle size and their size distribution. The average diameters of the Ag-NPs were $10.97,5.58$, and $3.16 \mathrm{~nm}$ for A2, A4, and A5, respectively. Moreover, X-ray diffraction analysis confirmed that the crystallographic planes of the silver crystal were of the face-centered cubic type. UV-visible absorption spectra showed the peak characteristic of the surface plasmon resonance bond of Ag-NPs. Scanning electron microscopy images demonstrate large layered surfaces for MMT, and short flaked surfaces for MT/Cts and Ag/MMT/Cts irradiated for 96 hours. Also, due to the presence of Ag-NPs in the external and internal surfaces of $\mathrm{Ag} / \mathrm{MMT} / \mathrm{Cts} \mathrm{BNCs}$ these layered become shining. Energy dispersive X-ray fluorescence spectra confirmed the presence of elemental compounds in the MMT, Cts, and Ag-NPs without any contamination peaks. Antibacterial activity of Ag/MMT/Cts BNCs was demonstrated, and showed strong antibacterial activity against Gram-positive and Gram-negative bacteria. Needless to say, further studies are required to investigate the bactericidal effects of $\mathrm{Ag} / \mathrm{MMT} / \mathrm{Cts} \mathrm{BNCs}$ on different types of bacteria for potential widening of this subject area, such as surgical devices or as drug delivery vehicles.

Table I Average inhibition zone and standard deviation for Ag/montmorillonite/chitosan bionanocomposites (A2, A4, and A5) and $\mathrm{AgNO}_{3}$ /montmorillonite/chitosan (A0)

\begin{tabular}{|c|c|c|c|c|c|c|c|c|}
\hline \multicolumn{5}{|c|}{ Inhibition zone (mm) } & \multicolumn{2}{|c|}{ Control negative (mm) } & \multicolumn{2}{|c|}{ Control positive $(\mathrm{mm})$} \\
\hline \multirow[t]{2}{*}{ Bacteria } & \multirow[t]{2}{*}{ A0 } & \multirow[t]{2}{*}{ A2 } & \multirow[t]{2}{*}{ A4 } & \multirow[t]{2}{*}{$\overline{A 5}$} & MMT & Cts & Cefotaxime & Chloramphenicol \\
\hline & & & & & $(5 \mathrm{mg} / \mathrm{mL})$ & $(0.2 \mathrm{mg} / \mathrm{mL})$ & & \\
\hline E. coli & 8.2 & 8.6 & 8.7 & 8.7 & $\mathrm{NA}^{*}$ & $\mathrm{NA}^{*}$ & 21.8 & 16.7 \\
\hline S. aureus & 8.4 & 8.5 & 8.6 & 8.8 & NA & NA & 23.6 & 16.4 \\
\hline MRSI & 8.2 & 8.3 & 8.4 & 8.6 & NA & NA & 18.9 & 15.5 \\
\hline
\end{tabular}

Notes: Mean standard deviation values for the $E$. coli $= \pm 0.16 \mathrm{~mm}, S$. aureus $= \pm 0.15 \mathrm{~mm}$ and $\mathrm{MRSI}= \pm 0.13 \mathrm{~mm}$ for $\mathrm{A} 0, \mathrm{~A} 2, \mathrm{~A} 4$, and $\mathrm{A} 5$.

Abbreviations: *NA, not appearing; MMT, montmorillonite; Cts, chitosan; MRSI, magnetic resonance spectroscopic imaging. 


\section{Acknowledgments}

The authors are grateful to the staff of the Department of Chemistry, Universiti Putra Malaysia, to Mrs Parvaneh Shabanzadeh, and to the Institute of Bioscience for technical assistance.

\section{Disclosure}

The authors have no conflicts of interest to disclose in this work.

\section{References}

1. Jubete E, Loaiza OA, Ochoteco E, et al. Nanotechnology: A tool for improved performance on electrochemical screen-printed (bio) sensors. Journal of Sensors. 2009:1-13.

2. Suh WH, Suslick KS, Stucky GD, et al. Nanotechnology, nanotoxicology, and neuroscience. Prog Neurobiol. 2009;87:133-170.

3. Murphy CJ. Sustainability as an emerging design criterion in nanoparticle synthesis and applications. J Mater Chem. 2008;18: 2173-176.

4. Aihara N, Torigoe K, Esumi K. Preparation and characterization of gold and silver nanoparticles in layered laponite suspensions. Langmuir. 1998;14:4945-4949.

5. Lin XZ, Teng X, Yang H. Direct synthesis of narrowly dispersed silver nanoparticles using a single-source precursor. Langmuir. 2003;19: 10081-10085.

6. Taleb A, Petit C, Pileni MP. Synthesis of highly monodisperse silver nanoparticles from AOT reverse micelles: A way to $2 \mathrm{D}$ and $3 \mathrm{D}$ selforganization. Chem Mater. 1997;9:950-959.

7. Dag O, Samarskays O, Coombs N, et al. The synthesis of mesostructured silica films and monoliths functionalised by noble metal nanoparticles. J Mater Chem. 2003;13:328-334.

8. Szlyk E, Piszczek P, Grodzicki A, et al. CVD of AgI complexes with tertiary phosphines and perfluorinated carboxylates - A new class of silver precursors. Chemical Vapor Deposition. 2001;7:111-116.

9. Schultz S, Smith DR, Mock JJ, Schultz DA. Single-target molecule detection with nonbleaching multicolor optical immunolabels. Proc Natl Acad Sci U S A. 2000;97:996-1001.

10. Rai M, Yadav A, Gade A. Silver nanoparticles: A novel antimicrobial agent. Biotechnol Adv. 2009;27:76-83.

11. Elechiguerra JL, Burt JL, Morones JR, et al. Interaction of silver nanoparticles with HIV-1. J Nanobiotechnology. 2005;3(6):1-10.

12. Crooks RM, Lemon BI, Sun L, et al. Dendrimer-encapsulated metals and semiconductors: Synthesis, characterization, and applications. Top Curr Chem. 2000;212:81-135.

13. Gittins DI, Bethell D, Nichols RJ, et al. Diode-like electron transfer across nanostructured films containing a redox ligand. J Mater Chem. 2000;10:79-83

14. Sharma VK, Yngard RA, Lin Y. Silver nanoparticles: Green synthesis and their antimicrobial activities. Adv Colloid Interface Sci. 2009; 145:83-96.

15. Huang NM, Radiman S, Lim HN, Khiew PS. $\gamma$-Ray assisted synthesis of silver nanoparticles in chitosan solution and the antibacterial properties. Chem Eng J. 2009;155(1-2):499-507.

16. Darroudi M, Ahmad MB, Shameli K, et al. Synthesis and characterization of UV-irradiated silver/montmorillonite nanocomposites. Solid State Sci. 2009;11:1621-1624.

17. Ahmad MB, Shameli K, Darroudi M, et al. Synthesis and characterization of silver/clay/chitosan bionanocomposites by UV-irradiation method. Am J Appl Sci. 2009;6:2030-2035.

18. Jingquan C, Suwei Y, Weiguo Z, et al. Preparation and characterization of silver colloids with different morphologies under ultrasonic field. Front Chem China. 2006;4:418-422.
19. Raveendran P, Fu J, Wallen SL. Completely "green" synthesis and stabilization of metal nanoparticles. J Am Chem Soc. 2003;125: 13940-13941.

20. Changa JH, Ana YU, Choa D, et al. Poly(lactic acid) nanocomposites: Comparison of their properties with montmorillonite and synthetic mica (II). Polymer. 2003;44:3715-3720.

21. Chang JH, An YU, Sur GS. Poly(lactic acid) nanocomposites with various organoclays. I. Thermomechanical properties, morphology, and gas permeability. J Polym Sci B Pol Phys. 2003;41: 94-103.

22. Giannelis EP, Krishnamoorti R, Manias E. Polymer-silicate nanocomposites: Model systems for confined polymers and polymer brushes. Adv Polym Sci. 1999;138:107-147.

23. Ramsay DF, Swanton SW, Bunce JJ. Swelling and dispersion of smectite caly colloids: Determination of structure by neutron diffraction and small-angle neutron scattering. J Chem Soc Faraday Trans. 1999; 86:3919-3926.

24. Ahmad MB, Shameli K, Darroudi M, et al. Synthesis and characterization of silver/clay nanocomposites by chemical reduction method. Am J Appl Sci. 2009;6:1909-1914.

25. Gao Y, Yunzhao Y. Deposition of silver nanoparticles on montmorillonite platelets by chemical plating. J Mater Sci. 2002;37:5083-5087.

26. Darder M, Colilla M, Ruiz-Hitzky E. Chitosan-clay nanocomposites: Application as electrochemical sensors. Appl Clay Sci. 2005;28: 199-208.

27. Zhou NL, Liu Y, Li L, et al. A new nanocomposite biomedical material of polymer/Clay-Cts-Ag nanocomposites. Curr Appl Phys. 2007; 7S1:e58-e62.

28. Medina RI, Bashirb S, Luoc Z, et al. Green synthesis and characterization of polymer-stabilized silver nanoparticles. Colloid Surf B Biointerfaces. 2009;73:185-191.

29. Zhu YJ, Qian Y, Li X, et al. $\gamma$-radiation synthesis and characterization of polyacrylamide-silver nanocomposites. Chem Commun. 1997;10: 1081-1082.

30. Bogle KA, Dhole SD, Bhoraskar VN. Silver nanoparticle: Synthesis and size control by electron irradiation. Nanotechnology. 2006;17: 3204-3208.

31. Janata E, Henglein A, Ershovt BG. First clusters of $\mathrm{Ag}^{+}$ion reduction in aqueous solution. J Phys Chem. 1994;98:10888-10890.

32. Janata E. Structure of the trimer silver $\mathrm{Ag}_{3}^{2+}$. J Phys Chem B. 2003; 107:7334-7336.

33. Kamat PV, Flumiani M, Hartland GV. Picosecond dynamics of silver nanoclusters. Photoejection of electrons and fragmentation. J Phys Chem B. 1998;102:3123-128.

34. Temgire MK, Joshi SS. Optical and structural studies of silver nanoparticles. Radiat Phys Chem. 2004;71:1039-1044.

35. Shin HS, Yang HJ, Kim SB, et al. Mechanism of growth of colloidal silver nanoparticles stabilized by polyvinyl pyrrolidone in $\gamma$-irradiated silver nitrate solution. J Colloid Interface Sci. 2004;274:89-94

36. Wu WT, Wang Y, Shi L, et al. Fabrication of silver/cross-linked poly(vinyl alcohol) cable-like nanostructures under gamma-ray irradiation. Nanotechnology. 2005;16:3017-3022.

37. Guang-Nian X, Xue-liang Q, Xiao-lin Q, et al. Preparation and characterization of stable monodisperse silver nanoparticles via photoreduction. Colloid Surface A. 2008;320:222-226.

38. Liu Z, Wang H, Wang LX. Red shift of plasmon resonance frequency due to the interacting Ag nanoparticle embedded in single crystal $\mathrm{SiO}_{2}$ by implantation. Appl Phys Lett. 1998;72:1823-1825.

39. Patakfalvi RA, Oszka A, Dekany I. Synthesis and characterization off silver nanoparticles/kaolinite composites. Colloid Surface Physicochem Eng Aspect. 2003;220:45-54.

40. Prasad V, Souza CD, Yadav D, Shaikh AJ, Vigneshwaran N. Spectroscopic characterization of zinc oxide nanorods synthesized by solid-state reaction. Spec Acta A: Mol Biomol Spec. 2006;65: $173-178$.

41. Huang H, Yang Y. Preparation of silver nanoparticles in inorganic clay suspensions. Compos Sci Technol. 2008;68:2948-2953. 
42. Harekrishna B, Dipak KB, Gobinda PS, et al. Green synthesis of silver nanoparticles using latex of Jatropha curcas. Colloid Surface A. 2009; 339:134-139.

43. Alemdar A, Güngör N, Ece ÖI, et al. The rheological properties and characterization of bentonite dispersions in the presence of non-ionic polymer PEG. J Mater Sci. 2005;40:171-177.

44. Ebru G, Pestreli D, Ünlü CH, et al. Synthesis and characterization of chitosan-MMT biocomposite systems. Carbohyd Polym. 2007;67: 358-365.
45. Darder M, Colilla M, Ruiz-Hitzky E. Biopolymer-clay nanocomposites based on chitosan intercalated in montmorillonite. Chem Mater. 2003; 15:3774-3780.

46. Lok CM, Ho CM, Chen R, et al. Proteomic analysis of the mode of antibacterial action of silver nanoparticles. J Proteome Res. 2006;5: 916-924.

\section{Publish your work in this journal}

The International Journal of Nanomedicine is an international, peerreviewed journal focusing on the application of nanotechnology in diagnostics, therapeutics, and drug delivery systems throughout the biomedical field. This journal is indexed on PubMed Central, MedLine, CAS, SciSearch ${ }^{\circledR}$, Current Contents ${ }^{\circledR} /$ Clinical Medicine,
Journal Citation Reports/Science Edition, EMBase, Scopus and the Elsevier Bibliographic databases. The manuscript management system is completely online and includes a very quick and fair peer-review system, which is all easy to use. Visit http://www.dovepress.com/ testimonials.php to read real quotes from published authors.

Submit your manuscript here: http://www.dovepress.com/international-journal-of-nanomedicine-journal 